\title{
Neuroscience education in Africa, prospects and challenges
}

\author{
Olabode Ekerin ${ }^{1(D)}$ and Calistus \\ Okechukwu K. ${ }^{2}$ \\ 1. Department of Paediatrics, Obafemi \\ Awolowo University Teaching \\ Hospitals Complex, Nigeria \\ 2. Department of Internal Medicine, \\ Obafemi Awolowo University \\ Teaching Hospitals Complex, Nigeria
}

Correspondence:

Olabode Ekerin

bodeekerin@gmail.com

Submitted: August 2021

Accepted: October 2021

Published: November 2021
Citation: Ekerin and Okechukwu. Neuroscience education in Africa, prospects and challenges. South Sudan Medical Journal 2021;14(4):127-131 (C) 2021 The Author (s) License: This is an open access article under CC BY-NC DOI: https://dx.doi.org/10.4314/ssmj.v14i4.5

\begin{abstract}
This review explores the scope of neuroscience education, the current and future trends and evaluates the limitations hindering the evolution of neuroscientific studies and research in Africa.

Neuroscience is one of the most poorly addressed fields of study in Africa evidenced by the paucity of available data. Africa has a lot to do to improve neuroscience research. More government financing is needed if the continent's research sector is to continue to expand. International scientific collaborations are an important part of integrating into the global research community. African neuroscientists must also participate in policy and decision-making to urge governments to finance research into Africa's specific requirements.
\end{abstract}

Keywords: Neuroscience, research, publication, education, Africa

\section{Introduction}

Neuroscience education in Africa started with the study of neuroanatomy and neurosurgery about 5000 years ago in Egypt. ${ }^{[1]}$ Through the mummification process, Egyptian embalmers were the first to learn about human anatomy. They had little regard for the brain and made no attempt to preserve it. ${ }^{[2,3]}$ Africa's research capability in this area has lagged behind the field's advancements. ${ }^{[4]}$ This is probably due to insufficient research facilities ${ }^{[5]}$, low financing ${ }^{[6]}$ and a small number of active neuroscientists. ${ }^{[7]}$ These impediments stifle African research and innovation ${ }^{[8]}$, contributing to a broader 'brain drain' ${ }^{[9]}$

Prior to formal education in neuroscience, herbal remedies for the management of mental illnesses and neurological disorders were the practice in African Countries like Nigeria. In the country's western region, concoctions known as Ajidewe and Ogun Isoye are believed to have anti-aging and memory-boosting properties ${ }^{[10]}$ Following colonialism, neurosurgery was brought to several African countries in the twentieth century and neurosurgery and neurology departments were created, although staffed by foreigners. ${ }^{[11]}$ Major advances have been made in neuroscience education and research as more African scholars have taken the opportunity to receive training from institutions abroad, while those who have been trained return home to utilize the knowledge acquired.

The Merriam-Webster Medical Dictionary defines neurobiology as the science of the nervous system. It incorporates the basic sciences: physiology, anatomy, biochemistry, molecular biology and computer science in the study of neurons and neural circuits and their relationship with learning, memory, consciousness and behaviour. In addition to cellular, molecular and clinical neuroscience, other constituent branches include neurogenetics, neural imaging, neuroanatomy, computational neuroscience and social neuroscience.

Globally, neurobiology is rapidly expanding in scope, coupled with a remarkable broadening of scientific approaches and techniques as well as clinical applications. It has evolved from cellular and molecular studies of neurons to include imaging of sensory, motor and cognitive functions of the brain. ${ }^{[12]}$ 


\section{Neuroscience Education in Africa}

Over the last century clinical investigations on neurogenetics and movement disorders dominated neuroscience research in Tunisia and Algeria. ${ }^{[13-16]}$ The study of behavioural consequences of brain injuries and nutritional insufficiency in rats introduced basic neuroscience research to Morocco in the 1970s. ${ }^{[17]}$ The closeness of North African neuroscientists to Middle Eastern and European training colleges encouraged them to continue their studies and contribute to the progress of neuroanatomy and neurosurgery. ${ }^{[18]}$ In the seventeenth century, Yoruba traditional healers in Nigeria are credited with developing the earliest knowledge of neurological disorders in Sub-Saharan Africa. ${ }^{[19]}$ In Nigeria, the first black African neuropsychiatrist developed a communitybased approach for psychiatric patients in the 1950s. [20] Early studies in Kenya were descriptive, focusing on brain size rather than function. ${ }^{[21]}$ Kenya witnessed the development of neurosurgical methods as a result of the two world wars. ${ }^{[22]}$

Neurosurgery advanced in the latter part of the twentieth century, with Kenyan neurosurgeons practicing and doing research. ${ }^{[22]}$ Epilepsy, infectious diseases, stroke, and the evaluation of the potential therapeutic efficacy of indigenous plant extracts have been a focus of research in Tanzania and Cameroon. ${ }^{[23-29]}$ The embryonic history of the segmented mesoderm and neural tube was the subject of South Africa's first publication on the nervous system. [30] Research on the neurophysiology of the spinal cord and on Cannabis sativa sparked basic and clinical progress in the 1950s and 1960s. ${ }^{[31-32]}$ The number of publications from African nations, such as South Africa, Egypt, and Nigeria, , has steadily increased ${ }^{[33]}$ although non-African authors account for over $70 \%$ from sub-Saharan Africa. ${ }^{[4]}$

Between 1996 and 2017 a limited number of nations have dominated Africa's neuroscience publications of 5219 articles: Egypt ((28\%), South Africa (23\%), Nigeria (11\%), Morocco (8\%), and Tunisia (7\%). (Figure 1a) These nations account for $77 \%$ of neuroscience articles published on the continent. East African nations Kenya, Ethiopia, and Tanzania contributed 2-3\% each, with Cameroon, Malawi, Algeria and Senegal, Uganda, and Ghana contributing 1-2\% each. However, the number of neuroscience articles published each year in Africa's key geopolitical areas has risen dramatically during the last two decades. (Figure 1b)

The most common research areas are neurodegeneration and injury $(n=2066,34 \%$; compared to $22 \%$ outside of Africa (OA)), techniques ( $\mathrm{n}=905,15 \%$; OA: 16\%), excitability, synapses, and glia $(n=550,9 \%$; OA: 15\%), development ( $\mathrm{n}=532,9 \%$; OA: 16\%), and physiology and behaviour ( $n=511,8 \%$; OA: 13\%) (Figure 1c). In contrast, research on motivation and emotion $(n=217$,
4\%; OA: 3\% ), motor systems ( $n=191,3 \%$; OA: 9\% ), cognition ( $\mathrm{n}=155,3 \%$; OA: $4 \%$ ), and sensory systems ( $n=92,2 \%$; OA: $2 \%)$ were less common.

International collaboration is an important part of integrating the global research community. ${ }^{[34]}$ Many African scholars have found it difficult to collaborate with colleagues in other countries due to a lack of funding and other obstacles. ${ }^{[35]}$ This greatly affects the visibility of African neuroscience researches. African-led neuroscience researches with foreign co-authors received more citations and were published in higher Impact Factor (IF) journals, both inside Africa and abroad. ${ }^{[36]}$

International, rather than local, agencies funded most African neuroscience papers. Southern Africa was the only African area where domestic financing outnumbered international funding. ${ }^{[34]}$ South Africa, the largest contributor in Southern Africa, is the only African country to invest nearly $1 \%$ of GDP in research and development, as the African Union recommended in 2007.. ${ }^{[37]}$ More government financing is needed to support the expansion of Africa's research industry. Local funding, in addition to, international funding, is critical for the development of a viable research culture in Africa.

Scientific success is highly dependent on access to cuttingedge research infrastructure, both technical and biological. Any plan for future research would require a knowledge of the availability and use of such tools throughout Africa. In Nigeria, none of the 153 institutions approved by the National Universities Commission (NUC) offers a neuroscience degree programme. $\left.{ }^{[38}\right]$ Medical students, on the other hand, take both basic and clinical neuroscience modules in some of their courses. ${ }^{[39]}$

Science-based non-profit organizations have sponsored training courses and workshops in neurosurgery, neurology, and basic neuroscience around Africa to support African neuroscientists and help build capacity for education and research. ${ }^{[1]}$ In Morocco and South Africa, International Brain Research Organization African Centres for Advanced Neuroscience Training have been established. World Federation of Neurosurgical Societies recognized Centres of Excellence for teaching neurosurgeons have also been established in Nigeria, Ivory Coast, Senegal, Kenya, Zimbabwe, and South Africa. ${ }^{[40]}$

For African neuroscience to grow, it requires continued international funding, and African neuroscientists must participate in policy and decision-making in order to urge governments to finance research of Africa's specific regional requirements. ${ }^{[41]}$ Increased participation in science advocacy efforts aimed at raising the visibility of African research and its relevance to both global and local issues might assist the cause of neuroscience research in Africa. This is important considering the genetic variation within the continent, which can aid the understanding of global 


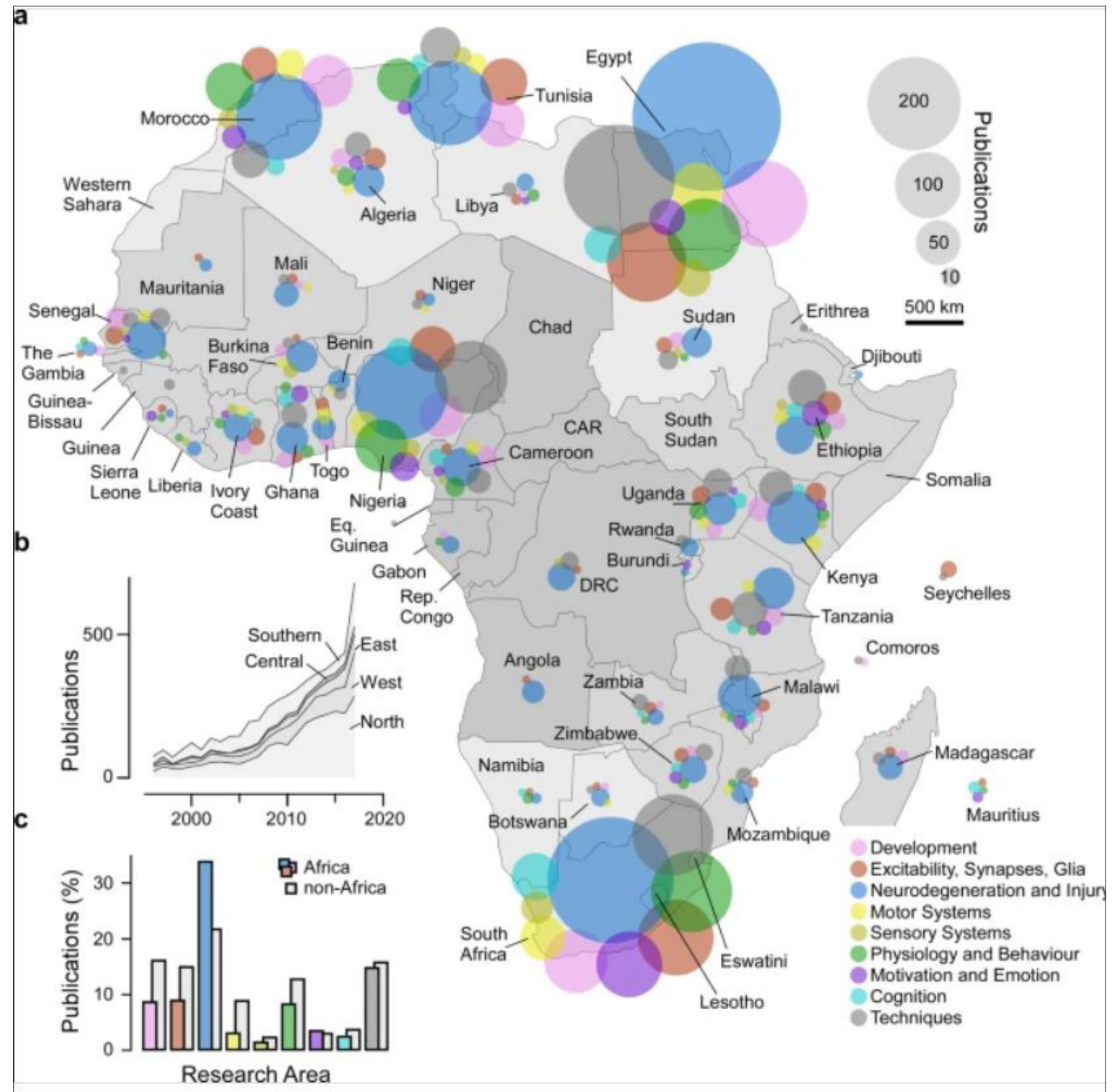

Figure. 1 African neuroscience publications 1996-2017. a: Overview of Africa's neuroscience publications, organised in nine broad topics as indicated by the different colours. Bubble sizes denote the total number of papers per country and topic. b: Total annual publications, with contributions from different African regions highlighted. Regions were delineated following the United Nations definition into North Africa, West Africa, East Africa, Central Africa and Southern Africa. See also background shading in (a). c: Distribution of research topics in Africa (coloured bars, for legend see (a)) and outside of Africa (grey bars). (M. B. Maina et al., 'Two decades of neuroscience publication trends in Africa', Nat. Commun., vol. 12, no. 1, 2021, doi: 10.1038/s41467-021-23784-8.)

health issues. ${ }^{[42]}$ Even though there is significant evidence of an increase in the number of neuroscience papers coming from Africa, there is much scope for improvement. There is significant variability in the visibility of neuroscience papers throughout the continent.

Among all the regions in Africa, West Africa appears to be lagging behind the rest of Africa. Nigeria, the nation with the most publications in the area, only produced one neuroscience piece in a journal with an IF of 9.5. ${ }^{[43]}$ The lack of visibility, particularly in terms of citations, may be explained partly by the where work is submitted for publication. Many Nigerian neuroscience publications are published in African journals with limited international recognition. ${ }^{[43]}$ Also PubMed database excludes a substantial proportion of African papers. ${ }^{[4]}$

Increased investment in modern research equipment, training in the use of technologies, and the use of genetically tractable models are all necessary to maintain this upward trend and raise the continent's neuroscience prominence. 


\section{Conflict of Interest: Nil}

Funding and Support: Nil

\section{References}

1. Russell VA. Notes on the Recent History of Neuroscience in Africa. Frontiers in Neuroanatomy 2017;11, 96. https://doi.org/10.3389/ fnana.2017.00096

2. Cappabianca P, Decq P, Schroeder HW. Future of endoscopy in neurosurgery. Surgical Neurology 2007;67(5), 496-498. https://doi.org/10.1016/j. surneu.2006.09.039

3. Elhadi A M, Kalb S, Perez-Orribo L. et al. The journey of discovering skull base anatomy in ancient Egypt and the special influence of Alexandria. Neurosurgical Focus 2012;33(2), E2. https://doi. org/10.3171/2012.6.FOCUS12128

4. Baskaran A. UNESCO Science Report: Towards 2030. 125-127 (Institutions and Economies, 2017) http:// uis.unesco.org/sites/default/files/documents/unescoscience-report-towards-2030-part1.pdf.

5. Petti CA, Polage CR, Quinn TC. et al Laboratory medicine in Africa: a barrier to effective health care. Clinical infectious diseases : an official publication of the Infectious Diseases Society of America 2006;42(3), 377-382. https://doi.org/10.1086/499363

6. Simpkin V, Namubiru-Mwaura E, Clarke L. et al . Investing in health $\mathrm{R} \& \mathrm{D}$ : where we are, what limits us, and how to make progress in Africa. BMJ Global Health 2019;4(2), e001047. https://doi.org/10.1136/ bmjgh-2018-001047

7. Okeke IN, Babalola CP, Byarugaba DK. et al. Broadening Participation in the Sciences within and from Africa: Purpose, Challenges, and Prospects. CBE life sciences education 2017;16(2), es2. https://doi. org/10.1187/cbe.15-12-0265

8. Graff G D, Pardey P G. Inventions and patenting in Africa: Empirical trends from 1970 to 2010. The Journal of World Intellectual Property 2020;23(1-2), 40-64. https://doi.org/10.1111/jwip.12139

9. Sefa Dei G J, Asgharzadeh A. What Is to Be Done? A Look at Some Causes and Consequences of the African Brain Drain. African Issues, 2002;30(1), 31-36. http:// doi.org/10.1017/S1548450500006272

10. Babawale OP, Taiwo F, Adetunj OS. Ethnobotanical Survey of Plants Used as Memory Enhancer in Three States of Southwestern Nigeria. J App Pharm Sci, 2016; 6 (09): 209-214. doi: 10.7324/JAPS.2016.60931.
11. El Khamlichi A. African Neurosurgery. Part I: Historical outline. Surgical neurology 1998;49(2), 222-227. https://doi.org/10.1016/s0090-3019(96)00422-3 .

12. Akil H, Balice-Gordon R, Cardozo, et al. Neuroscience Training for the 21st Century. Neuron 2016;90(5), $917-$ 926. https://doi.org/10.1016/j.neuron.2016.05.030 .

13. Tazir M, Geronimi C. Chronic childhood spinal muscular atrophies in Algeria. A genetic study. Journal of the Neurological Sciences 1990;96(1), 89-101. https://doi.org/10.1016/0022-510x(90)90059-v .

14. Hentati A, Bejaoui K., Pericak-Vance MA. et al. Linkage of recessive familial amyotrophic lateral sclerosis to chromosome 2q33-q35. Nature Genetics 1994;7(3), 425-428. https://doi.org/10.1038/ng0794-425 .

15. Gouider-Khouja N, Belal S, Hamida MB. et al. Clinical and genetic study of familial Parkinson's disease in Tunisia. Neurology 2000;54(8), 1603-1609. https:// doi.org/10.1212/wnl.54.8.1603 .

16. Younes-Mhenni S, Frih-Ayed M, Kerkeni A. et al. Peripheral blood markers of oxidative stress in Parkinson's disease. European Neurology 2007;58(2), 78-83. https://doi.org/10.1159/000103641

17. Bengelloun WA, Burright RG, DonovickPJ.Nutritional experience and spacing of shock opportunities alter the effects of septal lesions on passive avoidance acquisition by male rats. Physiology \& Behavior 1976;16(5), 583587. https://doi.org/10.1016/0031-9384(76)90219-5

18. El-Fiki M. African neurosurgery, the 21st-century challenge. World Neurosurgery 2020;73(4), 254-258. https://doi.org/10.1016/j.wneu.2010.02.012

19. Ogunniyi A. Chapter 50: history of tropical neurology. Handbook of Clinical Neurology 2010;95, 815-830. https://doi.org/10.1016/S0072-9752(08)02150-7 .

20. Lambo TA. Neuropsychiatric observations in the western region of Nigeria. British Medical Journal 1956;2(5006), 1388-1394. https://doi.org/10.1136/ bmj.2.5006.1388 .

21. Vint FW. The Brain of the Kenya Native. Journal of anatomy $1934 ; 68(\operatorname{Pt} 2), 216-223$.

22. Qureshi M M, Oluoch-Olunya D. History of neurosurgery in Kenya, East Africa. World Neurosurgery 2010;73(4), 261-263. https://doi.org/10.1016/j. wneu.2010.02.014 .

23. Matuja WB, Kilonzo G, Mbena P. et al. Risk factors for epilepsy in a rural area in Tanzania. A community-based case-control study. Neuroepidemiology 2001;20(4), 242-247. https://doi.org/10.1159/000054797 . 
24. Njamnshi AK, Blackett K N, Mbuagbaw J N. et al. Chronic Chlamydia pneumoniae infection and stroke in Cameroon: a case-control study. Stroke 2006;37(3), 796-799. https://doi.org/10.1161/01. STR.0000204223.04182.4a .

25. Njamnshi AK, Bissek AC, Ongolo-Zogo P. et al. Risk factors for $\mathrm{HIV}$-associated neurocognitive disorders (HAND) in sub-Saharan Africa: the case of YaoundéCameroon. Journal of the Neurological Sciences 2009;285(1-2), 149-153. https://doi.org/10.1016/j. jns.2009.06.043 .

26. Njamnshi AK, Seke Etet PF, Perrig S. et al. Actigraphy in human African trypanosomiasis as a tool for objective clinical evaluation and monitoring: a pilot study. PLoS Neglected Tropical Diseases 2012;6(2), e1525. https:// doi.org/10.1371/journal.pntd.0001525 .

27. Bum EN, Taiwe GS, Nkainsa LA. et al. Validation of anticonvulsant and sedative activity of six medicinal plants. Epilepsy \& Behavior; 14(3), 454-458. https:// doi.org/10.1016/j.yebeh.2008.12.022 .

28. Levira F, Thurman DJ, Sander JW. et al. Premature mortality of epilepsy in low- and middle-income countries: A systematic review from the Mortality Task Force of the International League Against Epilepsy. Epilepsia 2017;58(1), 6-16. https://doi.org/10.1111/ epi. 13603 .

29. Ngoupaye GT, Pahaye D B, Ngondi J. et al. Gladiolus dalenii lyophilisate reverses scopolamine-induced amnesia and reduces oxidative stress in rat brain. Biomedicine \& pharmacotherapy = Biomedecine $\&$ pharmacotherapie 2017;91, 350-357. https://doi. org/10.1016/j.biopha.2017.04.061 .

30. Dart RA. The Anterior End of the Neural Tube and the Anterior End of the Body. Journal of Anatomy 1924;58(Pt 3), 181-205.

31. Ames F. A clinical and metabolic study of acute intoxication with Cannabis sativa and its role in the model psychoses. The Journal of Mental Science 1958;104(437), 972-999. https://doi.org/10.1192/ bjp.104.437.972 .

32. Holemans KC, Meij HS, Meyer BJ. The existence of a monosynaptic reflex arc in the spinal cord of the frog. Experimental Neurology 1966;14(2), 175-186. https://doi.org/10.1016/0014-4886(66)90005-7 .

33. Abd-Allah F, Kissani N, William A. et al. Neuroscience research in Africa: Current status. eNeurologicalSci 2015;3, 7-10. https://doi.org/10.1016/j. ensci.2015.10.005.
34. Maina MB, Ahmad U, Ibrahim HA. et al. Two decades of neuroscience publication trends in Africa. Nature Communications 2021;12(1), 3429. https://doi. org/10.1038/s41467-021-23784-8 .

35. Waruru M. African and Asian researchers are hampered by visa problems. Nature 2018. https://doi. org/10.1038/d4158

36. Castillo JA, Powell MA. Research Impact and International Collaboration: A Study of Ecuadorian Science. Journal of Hispanic Higher Education 2020;19(3), 232-249. https://doi. org/10.1177/1538192718779169.

37. Simpkin V, Namubiru-Mwaura E, Clarke L. et al. Investing in health $\mathrm{R} \& \mathrm{D}$ : where we are, what limits us, and how to make progress in Africa. BMJ Global Health 2019;4(2), e001047. https://doi.org/10.1136/ bmjgh-2018-001047 .

38. Balogun W G, Cobham A E, Amin A. Neuroscience in Nigeria: the past, the present and the future. Metabolic Brain Disease 2018;33(2), 359-368. https://doi. org/10.1007/s11011-017-0119-9

39. Sanya EO, Ayodele O E, Olanrewaju TO. Interest in neurology during medical clerkship in three Nigerian medical schools. BMC Medical Education 2010;10, 36. https://doi.org/10.1186/1472-6920-10-36 .

40. Dechambenoit G. Action Africa! World Neurosurgery 2010;73(4), 251-253. https://doi.org/10.1016/j. wneu.2010.02.046

41. Bentivoglio M, Cavalheiro EA, Kristensson K. et al. Overview of neglected tropical diseases and conditions in the nervous system: past, present and perspectives, in Neglected Tropical Diseases and Conditions of the Nervous System 2014, New York, NY: Springer, 3-19. https://doi.org/10.1007/978-1-4614-8100-3_1

42. Campbell MC, Tishkoff SA. African genetic diversity: implications for human demographic history, modern human origins, and complex disease mapping. Annual Review of Genomics And Human Genetics 2008;9, 403-433. https://doi.org/10.1146/annurev. genom.9.081307.164258 .

43. Maina MB, Mohammed YG, Bukar, et al. African neuroscience on the global stage: Nigeria as a model. The European Journal of Neuroscience 2019;49(12), 1544-1551. https://doi.org/10.1111/ejn.14372 .

44. Goehl TJ, Flanagin A. Enhancing the quality and visibility of African medical and health journals. Environmental Health Perspectives 2008;116(12), A514-A515. https://doi.org/10.1289/ehp.12265 